\title{
Estabilidade e adaptabilidade de genótipos de algodão de fibra colorida quanto aos caracteres de fibra
}

\author{
Stability and adaptability of cotton genotypes of colorful fibers in relation \\ to the fiber characters
}

\author{
Luiz Paulo de Carvalho ${ }^{I^{*}}$ Caio Césio Salgado ${ }^{I I}$ Francisco José Correia Farias ${ }^{\mathrm{I}}$ \\ Vinícius Quintão CarneiroIII
}

\section{RESUMO}

O objetivo deste trabalho foi verificar a presença de interação genótipo x ambiente ( $G x A$ ) e determinar a adaptabilidade e estabilidade fenotípica de linhagens de algodão de fibra marrom, utilizando o modelo de Ebehart \& Russell. Foram conduzidos sete experimentos nos estados de CE, GO, MS e RN, em 2010 e 2011, em regime irrigado e de sequeiro. $O$ delineamento utilizado foi blocos casualizados com quatro repetições. Foram avaliados 11 genótipos, segundo sete caracteres relativos à fibra. A interação $G \times A$ foi significativa para a maioria dos caracteres. As linhagens 1, 2, 3, 4, 5 e 7 demonstraram capacidade de resposta à melhoria de ambiente, sendo 1 e 5 os genótipos que apresentaram comportamento previsivel para todas as características. $O$ indice de fibras curtas mostrou ser uma característica de alta previsibilidade.

Palavras-chave: melhoramento, fibra marrom, Gossypium hirsutum L. r. latifolium Hutch.

\section{ABSTRACT}

The objective of this study was to verify the presence of genotype $x$ environment $(G \times E)$ interaction and determine the adaptability and phenotypic stability of strains of brown cotton fiber using the model of Ebehart \& Russell. Seven experiments were conducted in the states of CE, GO, MS and RN, in 2010 and 2011 under irrigated and rain fed conditions. The experimental design was randomized blocks with four replications. Eleven genotypes were assessed according to seven characters on the fiber. The $G x$ E interaction was significant for most characters. The lines 1, 2, 3, 4, 5 and 7 showed better responsiveness to the environment, being 1 and 5 genotypes showed all predictable behavior characteristics for all characteristics. The content of short fibers proved to be a characteristic of high predictability.

Key words: improvement, brown fiber, Gossypium hirsutum L. $r$. latifolium Hutch.

\section{INTRODUÇÃO}

A cultura do algodão tem relevância para a economia brasileira e mundial, principalmente devido à obtenção da fibra têxtil. No Brasil, o quinto produtor mundial, a produção concentra-se no CentroOeste. Porém, no Nordeste, o algodão é também uma cultura de importância socioeconômica, sendo cultivado em regime de sequeiro ou de irrigação. No entanto, sua exploração em sequeiro constitui-se em uma atividade de risco devido à má distribuição das chuvas na região.

A produção de fibra de algodão no Brasil sempre se baseou no cultivo de cultivares de fibra branca, havendo cultivares de grande potencial produtivo e de boas características de fibra. Durante o século 20, o melhoramento do algodoeiro foi direcionado, em sua maioria, ao algodão branco. Já o de algodão de fibra colorida foi usado apenas artesanalmente ou como planta ornamental, principalmente nos Estados da Bahia e de Minas Gerais. Com o maior interesse na fibra colorida na Região Nordeste algumas cultivares de fibra colorida foram produzidas e são cultivadas na Região.

O línter e a fibra dos algodões tetraplóides ocorrem em cores que vão do branco a várias tonalidades de verde e marrom. Enquanto Gossypium hirsutum L. tipicamente possui fibra branca, G. barbadense L. frequentemente possui

'Centro Nacional de Pesquisa de Algodão (CNPA), Embrapa Algodão, 58107-720, Campina Grande, PB, Brasil. E-mail: luiz.carvalho@embrapa.br.

*Autor para correspondência.

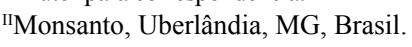

III Universidade Federal de Viçosa (UFV), Viçosa, MG, Brasil. 
fibra creme (PERCY \& KOHEL,1999). A herança da coloração da fibra normalmente é controlada por um gene dominante, mas com alelos em locos diferentes. O gene verde é controlado pelos alelos de um único locus $\mathrm{Lg}$, no cromossomo 15 do genoma D do algodão americano (G. hirsutum L.). O gene que controla a coloração marrom em suas várias tonalidades é encontrado nos algodões do velho e do novo mundo, com vários alelos identificados. Assim, sendo a cor do algodão controlada por genes maiores, o melhoramento dessa característica é simples, porém deve-se levar em conta que algumas tonalidades são fortemente influenciadas pelo ambiente (luz solar, tipo de solo, ano). Entre as tonalidades, a verde é a mais influenciada pelo ambiente, enquanto a creme e a marrom são as mais estáveis.

A interação genótipos $\mathrm{x}$ ambientes $(\mathrm{G}$ $\mathrm{x}$ A) é um dos maiores desafios no melhoramento de plantas, tanto nos procedimentos de seleção quanto na recomendação de cultivares, sendo que os melhoristas normalmente procuram por genótipos estáveis e produtivos (SUINAGA et al., 2006). Estudos de interação $\mathrm{G} \times \mathrm{A}$ em algodão são escassos no Brasil, principalmente para algodão com fibra colorida, sendo a maioria deles efetuados na Região Nordeste (MOREIRA et al., 1983; SANTANA et al., 1983; CARVALHO et al., 1995; FARIAS et al., 1997) e apenas alguns realizados na Região Centro-Oeste: SOBREIRA et al. (2003); MORELLO et al. (2005); SOUZA et al. (2006); e SILVA FILHO et al. (2008). NG et al. (2013) estudaram a adaptabilidade de 31 genótipos de algodoeiro no Texas, conseguindo-se identificar os melhores locais para avaliação de rendimento, percentagem de fibra, resistência e comprimento de fibra. Estes autores encontraram ainda associação positiva entre produção e percentagem de fibra e negativa entre caracteres de produção e comprimento de fibra.

O objetivo deste trabalho foi verificar a presença de interação genótipos $\mathrm{x}$ ambientes $\mathrm{e}$ determinar a adaptabilidade e estabilidade fenotípica de 11 genótipos de algodão ( $\boldsymbol{G}$. hirsutum L. r. latifolium Hutch) de fibra marrom, em regime irrigado e de sequeiro, utilizando o modelo proposto por EBEHART \& RUSSELL (1966).

\section{MATERIAL E MÉTODOS}

Foram conduzidos sete experimentos nos estados do CE, RN, GO e MS. Dois experimentos foram conduzidos em Barbalha-CE, nos anos de 2010 e 2011, cultivados na estação da seca e irrigados por sulco durante todo o ciclo; dois em Apodi-RN, nos mesmos anos, cultivados no período das chuvas, porém com três irrigações complementares de $15 \mathrm{~mm}$ cada, devido à estiagem ocorrida na região; um em Ipanguassú-RN, irrigado por aspersão durante todo o ciclo; um em Itaquiraí-MS e outro em Santa Helena-GO, ambos em regime de sequeiro.

Foram utilizadas nove linhagens de fibra de cor marrom e duas testemunhas. Estas são a 'BRS Rubi', cultivar de fibra marrom escura, e a 'BRS Aroeira'de fibra branca. A cultivar 'BRS Rubi' possui a fibra marrom mais escuro entre todas as outras com bastante acúmulo de pigmentos relativos a essa cor. Todas as outras nove linhagens de fibra colorida são originárias de cruzamentos da 'BRS Rubi' com cultivares de fibra branca, em programas de melhoramento genético, e utilizadas em plantios no Brasil. A fibra destas linhagens é de um marrom mais claro, portanto com menos acúmulo de pigmentos na fibra.

Os ensaios foram conduzidos em blocos casualizados com quatro repetições. Cada parcela foi composta por duas linhas de 5,0m espaçadas em $1,0 \mathrm{~m}$. Os caracteres avaliados foram comprimento em termos de uniformidade do comprimento de fibra (UHM), uniformidade da fibra (\%) (UNI), resistência da fibra em gf/tex (RES), finura da fibra em "micronaire" (FIN), maturidade da fibra (\%) (MAT), percentagem de fibra (\%) (PF) e índice de fibras curtas (\%) (IFC). Na colheita foram retirados 20 capulhos para a determinação dos caracteres de fibra realizada em HVI ("High volume instrument"), o aparelho eletrônico atualmente utilizado para medição dos caracteres de fibra.

Foi realizada análise individual, obtendo-se o quadrado médio residual de cada experimento. Como a razão entre o maior e o menor quadrado médio não ultrapassou sete, os ensaios puderam ser analisados conjuntamente (GOMES, 1987). A análise de adaptabilidade e estabilidade foi realizada pelo modelo de regressão proposto por EBEHART \& RUSSELL (1966). As análises dos dados foram realizadas no programa GENES (CRUZ 2006). Adotou-se o modelo de regressão linear $\mathrm{Y}_{\mathrm{ij}}=\beta_{0+} \beta_{1 \mathrm{i}} \mathrm{I}_{\mathrm{j}+} \delta_{\mathrm{ij}+}$ $\varepsilon_{\mathrm{ij}}$, sendo $\mathrm{Y}_{\mathrm{ij}}$, a média do genótipo i no ambiente $\mathrm{j}$; $\beta_{0 \mathrm{i}}$ a média geral do genótipo $\mathrm{i} ; \beta_{1 \mathrm{i}}$ o coeficiente de regressão linear que mede a resposta do i-ésimo genótipo à variação ambiental; $\mathrm{I}_{\mathrm{j}}$, o índice ambiental codificado $\left(\sum_{j} I_{j}=0\right) ; \delta_{i}$, o desvio da regressão; e $\varepsilon_{\mathrm{ij}}$, o erro experimental médio.

Ciência Rural, v.45, n.4, abr, 2015. 


\section{RESULTADOS E DISCUSSÃO}

A interação $G$ x A das onze linhagens avaliadas é evidenciada pela análise de variância na tabela 1. Observa-se que há variabilidade entre os materiais avaliados, devido à significância estatística para genótipos em relação a todas as características de fibra avaliadas. A interação $\mathrm{G}$ x A também foi significativa para todos os caracteres de fibra avaliados, evidenciando que as linhagens se comportam diferentemente nos vários ambientes. Esta mudança de ordem de performance dos materiais foi verificada para as diversas linhagens avaliadas, com destaque para as linhagens 1, 2, 3, 4 e 8 para determinados caracteres (Figura 1).

O genótipo 1, quando avaliado para o índice de fibras curtas, respondeu ao ambiente favorável e obteve média igual à da 'BRS Rubi', que obteve uma das maiores médias, com $\mathrm{R}^{2}$ de 0,98 (Tabela 2). Os genótipos 1 e 10 respondem bem à melhoria de ambiente quanto à porcentagem de fibra com $\mathrm{R}^{2}=0,98$, em relação ao genótipo 10 , 'BRS Aroeira', embora em ambiente favorável, este último apresente média estatisticamente maior que os outros citados. Quanto à resistência da fibra, a linhagem 1 apresenta resposta positiva à melhoria do ambiente e obteve média inferior à da testemunha 'BRS Aroeira' quando avaliado em ambiente favorável. A linhagem 2, quanto à maturidade da fibra, responde à melhoria de ambiente, embora sua média nesta condição seja inferior estatisticamente à da 'BRS Aroeira'. A linhagem 3 respondeu significativamente à melhoria de ambiente com $\mathrm{R}^{2}=0,89$, em relação à finura da fibra, porém apresentou média inferior à da testemunha 'BRS Aroeira' em ambiente favorável. A linhagem 4 apresentou média de comprimento da fibra superior à da 'BRS Rubi', mas responde bem ao ambiente favorável, chegando a obter média próxima à 'BRS Aroeira', com um coeficiente de confiabilidade de $\mathrm{R}^{2}=0,96$. Para uniformidade da fibra, o genótipo 8 respondeu à melhoria de ambiente, apresentando média igual à da cultivar 'BRS Rubi', mas responde muito bem à melhoria de ambiente e é sensível a ambientes desfavoráveis.

Quando avaliadas no ambiente mais favorável (Tabela 3), diversas linhagens demonstraram bom comportamento, com médias próximas e/ou superiores às das testemunhas. Neste ambiente, a testemunha 'BRS Aroeira' se sobressaiu sobre os demais genótipos para todas as características, com exceção do IFC, que apresentou a menor média, porém não diferindo estatisticamente de outras oito linhagens. Menor índice de fibras curtas é desejável. Para todas as características, houve alguma linhagem superior à cultivar 'BRS Rubi', sendo algumas com médias significativamente iguais à 'BRS Aroeira'. Entre estas, destacam-se os genótipos 4, 5, 8 e 9, pois estes apresentaram médias significativamente mais elevadas para dois caracteres avaliados.

$\mathrm{O}$ baixo valor de $\mathrm{R}^{2}$ encontrado para a cultivar 'Rubi', quanto à resistência da fibra, pode ser explicado pela possível não linearidade da variação em relação às variáveis ambientais, no caso da fibra colorida e em particular da cultivar 'BRS Rubi', que possui grande acúmulo de pigmento marrom na fibra. $\mathrm{Na}$ análise de variância, não houve muita variação residual, pois foi baixo o coeficiente de variação para a resistência da fibra. Fato semelhante ocorreu com o comprimento e a uniformidade da fibra para a mesma cultivar.

Segundo CARVALHO \& SANTOS (2003), a seleção para cores mais intensas piora as

Tabela 1 - Análise de variância conjunta dos caracteres de fibra em sete ensaios de genótipos de algodão de fibra colorida conduzidos nas Regiões Nordeste e Centro-Oeste, em 2010 e 2011.

\begin{tabular}{|c|c|c|c|c|c|c|c|c|}
\hline \multirow{2}{*}{ FV } & \multirow{2}{*}{ GL } & \multicolumn{7}{|c|}{-Quadrado Medio } \\
\hline & & $\mathrm{COM}$ & UNI & RES & FIN & MAT & IFC & $\mathrm{PF}$ \\
\hline Genótipos (G) & 10 & $41,39 * *$ & $43,17 * *$ & $166,37 * *$ & $7,63 * *$ & $44,66 * *$ & $35,39 * *$ & $100,78^{* *}$ \\
\hline Ambientes (A) & 6 & $69,05 * *$ & $51,20 * *$ & $133,45^{* *}$ & $20,65^{* *}$ & $137,77 * *$ & $499,36^{* *}$ & $398,98 * *$ \\
\hline GX A & 60 & $2,22 * *$ & $3,04 * *$ & $8,02 * *$ & $0,27 * *$ & $2,38 * *$ & $5,10^{*}$ & $12,99 * *$ \\
\hline Resíduo & 210 & 0,80 & 1,41 & 3,98 & 0,12 & 0,83 & 3,37 & 2,15 \\
\hline $\mathrm{CV}(\%)$ & - & 3,26 & 1,44 & 7,61 & 8,50 & 1,06 & 26,81 & 3,90 \\
\hline
\end{tabular}

**,*Significativo a $1 \%$ e $5 \%$ de probabilidade pelo teste $\mathrm{F}$, respectivamente.

COM, comprimento de fibra; UNI, uniformidade da fibra; RES, resistência da fibra; FIN, finura da fibra; MAT, maturidade da fibra; IFC, índice de fibras curtas e PF, percentagem de fibra. 

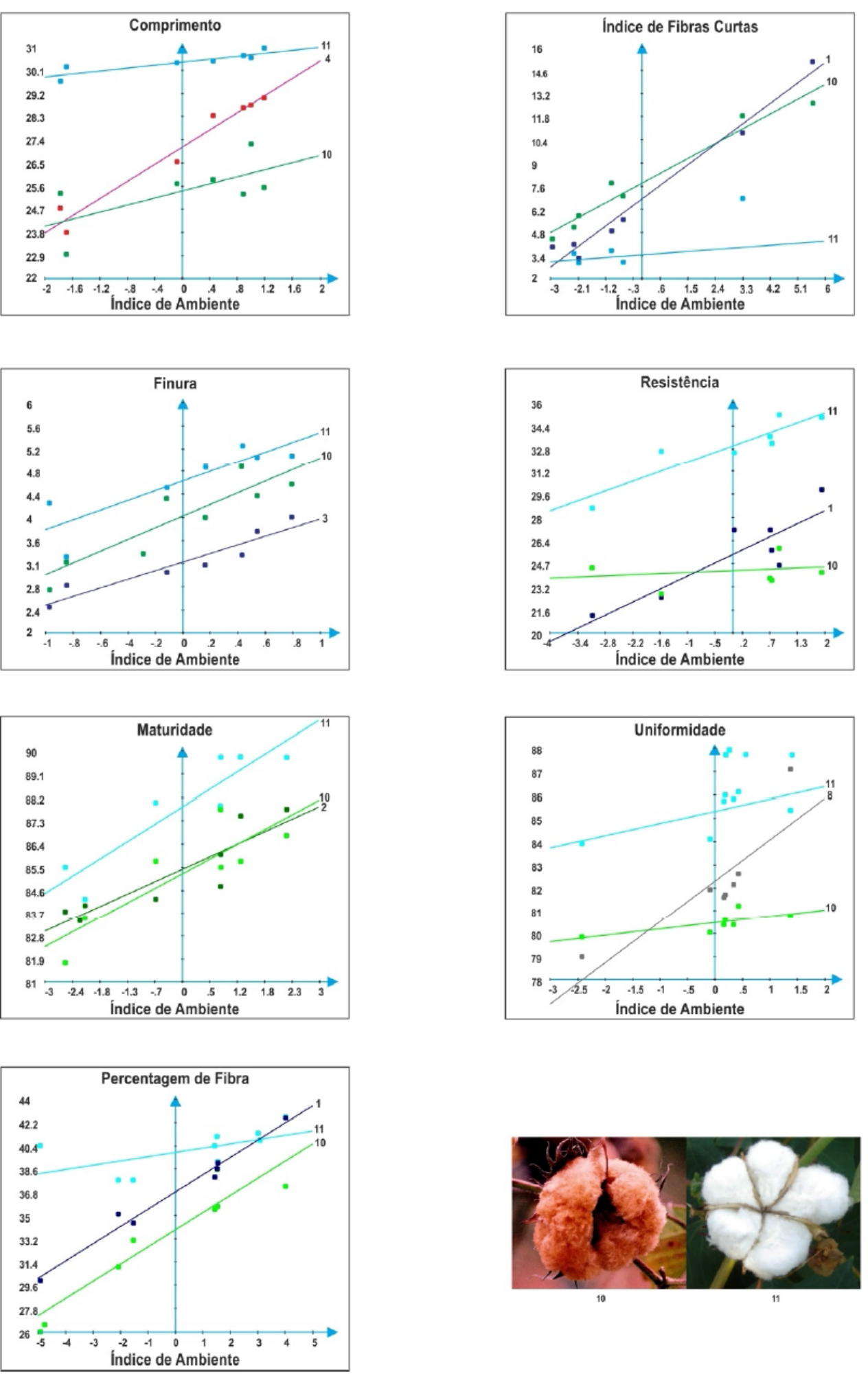

Figura 1 - Comportamento de genótipos de algodão de fibra colorida em relação a sete caracteres de fibra em diferentes ensaios conduzidos nas Regiões Nordeste e Centro-Oeste, em 2010 e 2011 (Barbalha-CE, Apodi-RN, Ipanguaçu-RN, Santa Helena-GO e Itaquiraí-MS). 
Tabela 2 - Médias de caracteres de 11 genótipos de algodão de fibra colorida e coeficiente de determinação em sete ensaios conduzidos nas Regiões Nordeste e Centro-Oeste, em 2010 e 2011 (Barbalha-CE, Apodi-RN, Ipanguaçu-RN, Santa Helena-GO e Itaquiraí-MS).

\begin{tabular}{|c|c|c|c|c|c|c|c|c|c|c|c|c|c|c|}
\hline \multirow{2}{*}{$\mathrm{G}$} & \multicolumn{2}{|c|}{------COM------ } & \multicolumn{2}{|c|}{--------UNI------- } & \multicolumn{2}{|c|}{-------RES------ } & \multicolumn{2}{|c|}{-------FIN------- } & \multicolumn{2}{|c|}{------MAT------ } & \multicolumn{2}{|c|}{---------IFC-------- } & \multicolumn{2}{|c|}{--------PF-------. } \\
\hline & M & $\mathrm{R}^{2}$ & M & $\mathrm{R}^{2}$ & M & $\mathrm{R}^{2}$ & $\mathrm{M}$ & $\mathrm{R}^{2}$ & M & $\mathrm{R}^{2}$ & M & $\mathrm{R}^{2}$ & M & $\mathrm{R}^{2}$ \\
\hline 1 & 27,00 & 93,67 & 81,65 & 90,53 & 25,46 & 79,94 & 3,77 & 97,60 & 84,86 & 93,71 & 6,80 & 98,11 & 36,82 & 97,94 \\
\hline 2 & 26,99 & 90,23 & 81,47 & 64,02 & 25,35 & 70,09 & 3,74 & 77,52 & 85,43 & 77,34 & 7,42 & 97,99 & 38,05 & 77,90 \\
\hline 3 & 27,59 & 84,46 & 82,05 & 77,30 & 25,25 & 35,84 & 3,23 & 89,26 & 84,0 & 78,64 & 7,61 & 88,90 & 35,63 & 88,17 \\
\hline 4 & 27,13 & 96,18 & 82,27 & 31,30 & 25,24 & 74,50 & 3,51 & 86,98 & 84,61 & 90,42 & 7,57 & 83,75 & 36,25 & 80,80 \\
\hline 5 & 28,31 & 83,39 & 83,01 & 86,23 & 26,55 & 63,80 & 4,32 & 95,13 & 85,79 & 97,57 & 5,5 & 96,13 & 37,88 & 95,91 \\
\hline 6 & 27,18 & 83,97 & 82,51 & 29,90 & 27,92 & 90,10 & 4,75 & 98,42 & 87,68 & 95,09 & 5,95 & 93,43 & 38,79 & 88,44 \\
\hline 7 & 27,64 & 70,72 & 82,05 & 80,22 & 25,55 & 58,15 & 4,11 & 97,82 & 85,90 & 97,71 & 7,59 & 89,66 & 36,90 & 83,77 \\
\hline 8 & 26,91 & 90,49 & 81,53 & 84,76 & 24,85 & 79,29 & 4,73 & 90,87 & 86,36 & 88,13 & 6,94 & 90,30 & 40,24 & 56,55 \\
\hline 9 & 27,26 & 85,29 & 81,33 & 85,05 & 25,04 & 63,98 & 4,60 & 88,73 & 86,68 & 92,38 & 7,81 & 91,93 & 39,29 & 74,08 \\
\hline 10 & 25,42 & 44,53 & 80,47 & 51,83 & 24,32 & 5,46 & 4,02 & 83,75 & 85,25 & 71,74 & 7,80 & 94,46 & 33,89 & 86,13 \\
\hline 11 & 30,44 & 78,55 & 85,3 & 51,99 & 32,99 & 81,02 & 4,62 & 75,01 & 88,13 & 63,91 & 4,36 & 95,26 & 39,59 & 26,79 \\
\hline M & 27,44 & - & 82,15 & - & 26,23 & - & 4,13 & - & 85,88 & - & 6,85 & - & 37,57 & - \\
\hline
\end{tabular}

Testemunhas: Genótipo 10 = 'BRS Rubi'; Genótipo 11= 'BRS Aroeira'; G = genótipo; M = média; COM, comprimento de fibra (UHM); UNI, uniformidade da fibra (\%); RES, resistência da fibra (gf/tex); FIN, finura da fibra (micronaire); MAT, maturidade da fibra (\%); IFC, índice de fibras curtas (\%) e PF, percentagem de fibra (\%).

características de fibra. Neste trabalho, a cultivar 'BRS Rubi' possui a fibra mais escura entre as demais linhagens. Observa-se que a cultivar 'BRS Rubi' obteve as menores médias para comprimento da fibra, uniformidade do comprimento, resistência da fibra e percentagem de fibra. Já a testemunha, 'BRS Aroeira', obteve as maiores médias para a maioria das características avaliadas como comprimento da fibra, uniformidade da fibra, resistência da fibra e maturidade da fibra. Porém, para índice de fibras curtas, esta cultivar apresentou a média mais baixa dentre os genótipos, o que é desejável. Dentre as linhagens resultantes do programa de melhoramento, algumas apresentaram médias superiores a cultivar 'BRS Rubi', evidenciando a melhoria genética dos genótipos, já que estes são originários do cruzamento da 'BRS Rubi' com cultivares de fibra branca.

Quanto à análise de adaptabilidade e estabilidade, observou-se, na tabela 4 , que a cultivar 'BRS Aroeira' apresentou $\beta$ significativamente igual a 1 para certos caracteres, evidenciando a

Tabela 3 - Caracteres de fibra de algodão em sete ensaios, em ambiente favorável, nas Regiões Nordeste e Centro-Oeste, em 2010 e 2011.

\begin{tabular}{|c|c|c|c|c|c|c|c|}
\hline GEN & $\mathrm{COM}$ & UNI & RES & FIN & MAT & IFC & $\mathrm{PF}$ \\
\hline 1 & $29,1000 \mathrm{abc}^{*}$ & $81,6000 \mathrm{abc}$ & $29,9250 \mathrm{~b}$ & $2,7000 \mathrm{~d}$ & $82,7500 \mathrm{~cd}$ & $5,5750 \mathrm{bc}$ & $29,9400 \mathrm{def}$ \\
\hline 2 & $28,8000 \mathrm{bc}$ & $82,7750 \mathrm{ab}$ & $27,7500 \mathrm{bc}$ & $2,8500 \mathrm{~cd}$ & $83,7500 \mathrm{bcd}$ & $7,1000 \mathrm{abc}$ & $32,9275 \mathrm{~cd}$ \\
\hline 3 & $28,9250 \mathrm{bc}$ & $82,4000 \mathrm{abc}$ & $25,7500 \mathrm{bc}$ & $2,4500 \mathrm{~d}$ & $82,0000 \mathrm{~cd}$ & $7,8000 \mathrm{ab}$ & 28,7650 efg \\
\hline 4 & $29,0250 \mathrm{abc}$ & $80,2750 \mathrm{bc}$ & $25,6500 \mathrm{bc}$ & $2,4000 \mathrm{~d}$ & $81,7500 \mathrm{~d}$ & $10,0750 \mathrm{a}$ & $27,5225 \mathrm{fg}$ \\
\hline 5 & $29,8500 \mathrm{ab}$ & 83,7750 a & $28,5750 \mathrm{bc}$ & $3,1000 \mathrm{bcd}$ & $83,0000 \mathrm{bcd}$ & $4,6000 \mathrm{bc}$ & $31,2975 \mathrm{de}$ \\
\hline 6 & $27,9250 \mathrm{bc}$ & $82,5250 a b c$ & $29,8750 \mathrm{~b}$ & $3,6500 \mathrm{ab}$ & $85,0000 \mathrm{~b}$ & $5,4750 \mathrm{bc}$ & $34,9325 \mathrm{bc}$ \\
\hline 7 & $29,4500 \mathrm{abc}$ & $82,3750 a b c$ & $27,7750 \mathrm{bc}$ & $2,9750 \mathrm{bcd}$ & $83,0000 \mathrm{bcd}$ & $6,5500 \mathrm{abc}$ & $30,4525 \mathrm{def}$ \\
\hline 8 & $27,4250 \mathrm{~cd}$ & $81,9250 \mathrm{abc}$ & $26,1000 \mathrm{bc}$ & $3,9750 \mathrm{a}$ & $84,0000 \mathrm{bc}$ & $4,6000 \mathrm{bc}$ & $39,7425 \mathrm{a}$ \\
\hline 9 & $27,9750 \mathrm{bc}$ & $81,5750 \mathrm{abc}$ & $28,7000 \mathrm{bc}$ & $3,6000 \mathrm{abc}$ & $83,7500 \mathrm{bcd}$ & $5,8250 \mathrm{bc}$ & $37,4675 \mathrm{ab}$ \\
\hline 10 & $25,5500 \mathrm{~d}$ & $80,0500 \mathrm{c}$ & $24,2000 \mathrm{c}$ & $2,7500 \mathrm{~d}$ & $81,7500 \mathrm{~d}$ & $7,0250 \mathrm{abc}$ & $26,0650 \mathrm{~g}$ \\
\hline 11 & $30,9750 \mathrm{a}$ & $84,1250 \mathrm{a}$ & $35,0000 \mathrm{a}$ & $4,2500 \mathrm{a}$ & $87,5000 \mathrm{a}$ & $3,0000 \mathrm{c}$ & $40,4050 \mathrm{a}$ \\
\hline
\end{tabular}

*Valores seguidos pela mesma letra, na vertical, não diferem significativamente pelo teste Tukey a $5 \%$ de probabilidade.

Testemunhas: G10 = 'BRS Rubi'; G11= 'BRS Aroeira';

GEN, Genótipo; COM, comprimento de fibra (UHM); UNI, uniformidade da fibra (\%); RES, resistência da fibra (gf/tex); FIN, finura da fibra (micronaire); MAT, maturidade da fibra (\%); IFC, índice de fibras curtas(\%); PF, percentagem de fibra (\%). 
Tabela 4 - Estimativa dos coeficientes de regressão ( $\beta$ ) em análise de estabilidade pelo modelo de EBEHART \& RUSSELL (1966) em 11 genótipos de algodão de fibra colorida em sete ensaios conduzidos nas Regiões Nordeste e Centro-Oeste, em 2010 e 2011.

\begin{tabular}{|c|c|c|c|c|c|c|c|}
\hline Genótipo & $\mathrm{COM}$ & UNI & RES & FIN & MAT & IFC & $\mathrm{PF}$ \\
\hline 1 & $1,2811 *$ & $1,244^{*}$ & 1,5259 & $1,0735^{*}$ & $0,9795 *$ & 1,3107 & 1,3372 \\
\hline 2 & 1,3134 & $1,1511^{*}$ & $1,0775^{*}$ & $0,9237 *$ & $0,8295^{*}$ & $1,1089 *$ & $0,9919 *$ \\
\hline 3 & $1,0887 *$ & $1,4357^{*}$ & $0,7068 *$ & 0,731 & 0,7957 & $0,9809 *$ & 1,272 \\
\hline 4 & 1,6639 & $0,6898^{*}$ & $1,2122 *$ & $1,0154 *$ & $1,0631^{*}$ & $1,0315^{*}$ & 1,3019 \\
\hline 5 & $0,8894 *$ & $1,4331^{*}$ & $0,8891 *$ & $0,9873^{*}$ & $1,0045^{*}$ & $1,0043^{*}$ & 1,1957 \\
\hline 6 & $0,7885^{*}$ & 0,5085 & $1,1486^{*}$ & $1,1513 *$ & $1,1574 *$ & $0,876^{*}$ & $1,0094 *$ \\
\hline 7 & $1,0482 *$ & 1,4545 & $0,9628 *$ & $1,1209^{*}$ & $1,1427^{*}$ & $1,0052 *$ & $1,0667^{*}$ \\
\hline 8 & $0,8939 *$ & $0,9979 *$ & $1,1139^{*}$ & $1,1363^{*}$ & $1,0298^{*}$ & $0,9846^{*}$ & 0,5086 \\
\hline 9 & $1,0644 *$ & $1,1752^{*}$ & $1,0896 *$ & $0,9951 *$ & $1,1407^{*}$ & $1,0912 *$ & 0,5972 \\
\hline 10 & 0,6791 & 0,3047 & 0,1459 & $1,0209 *$ & $0,9648 *$ & $0,933 *$ & 1,3195 \\
\hline 11 & 0,2893 & $0,6054^{*}$ & $1,1278 *$ & $0,8445^{*}$ & $0,8923^{*}$ & 0,6737 & 0,4 \\
\hline
\end{tabular}

*Significativamente igual a 1,0 pelo teste $\mathrm{t}$ a $5 \%$ de probabilidade.

COM, comprimento de fibra (UHM); UNI, uniformidade da fibra; RES, resistência da fibra; FIN, finura da fibra; MAT, maturidade da fibra; IFC, índice de fibras curtas; e PER, percentagem de fibra.

ampla adaptabilidade deste genotipo. Esta cultivar apresentou adaptabilidade a ambientes desfavoráveis para comprimento de fibra, índice de fibras curtas e percentagem de fibra, e também a ambientes favoráveis, pois obteve a maior média para seis caracteres em ambientes favoráveis. Embora a cultivar 'BRS Rubi' possua médias menores que as demais coloridas para muitos caracteres em ambientes favoráveis, esta responde à melhoria de ambiente para vários caracteres. As linhagens, em geral, apresentaram adaptabilidade ampla para a maioria das características. Para as linhagens 1, 2, $3,4,5$ e 7 , obteve-se $\beta$ significativamente superior a 1 para certos caracteres, demonstrando capacidade de resposta à melhoria de ambiente. Entre estas, destacam-se a 1 e a 4, que apresentaram este comportamento para mais de uma característica. A linhagem 1 mostrou adaptabilidade a ambientes favoráveis para resistência da fibra, índice de fibras curtas e percentagem de fibras. Já para a linhagem 4, este comportamento foi observado para os caracteres comprimento e percentagem de fibras.

Segundo CRUZ et al. (2004), índices de estabilidade igual a zero ou próximo de zero evidenciam previsibilidade na expressão fenotípica do caráter. Dentre as características avaliadas, a percentagem de fibra mostrou ser de baixa previsibilidade, sendo nove genótipos com $\sigma^{2}{ }_{\mathrm{di}}$ significativamente diferente de zero (Tabela 5). Já o índice de fibras curtas apresentou alta previsibilidade, sendo somente o genótipo 4 de baixa previsibilidade para esta característica. Certas linhagens mostraramse previsíveis para todas as características, como os genótipos 1 e 5 . Porém, outras linhagens, como a 2 e a 3 , demonstraram serem pouco previsíveis para 4 das características.

Os resultados evidenciam a complexidade da interação quando se trata de fibra colorida, fazendo com que se tenha que avaliar os genótipos em amostras adequadas de ambientes para os quais os materiais estão sendo desenvolvidos. As variáveis ambientais são classificadas como previsíveis e imprevisíveis (ALLARD \& BRADSHAW, 1964). Tipos de solo e data de plantio, por exemplo, estão na primeira categoria mas chuvas, temperatura e umidade relativa, por outro lado, na segunda. Os fatores imprevisíveis contribuem para a interação de genótipos com locais e anos (FEHR, 1987). Estes resultados sugerem que, como constantemente são lançadas cultivares devido à nova cor que apresentam, é necessário avaliá-las em mais locais e anos. Grandes mudanças na performance dos genótipos em diferentes locais sugerem que é desejável desenvolver genótipos para diferentes locais.

\section{CONCLUSÃO}

A interação genótipos $\mathrm{x}$ ambientes se faz presente para a maioria dos caracteres de fibra do algodoeiro de fibra colorida e é de natureza complexa, já que há variação no ordenamento dos genótipos nos vários ambientes. As linhagens, em geral, apresentaram adaptabilidade ampla para a maioria das características de fibra. Dentre estas, as $1,2,3,4,5$ e 7 demonstraram capacidade de 
Tabela 5 - Desvios da regressão $\quad \sigma_{\text {di }}^{2}$ em análise de estabilidade de EBEHART \& RUSSELL (1966) para os vários caracteres de fibra de algodão em sete ensaios conduzidos nas Regiões Nordeste e Centro-Oeste, em 2010 e 2011.

\begin{tabular}{|c|c|c|c|c|c|c|c|}
\hline Genótipo & COM & UNI & RES & FIN & MAT & IFC & $\mathrm{PF}$ \\
\hline 1 & $0,0086^{\mathrm{ns}}$ & $-0,1253^{\mathrm{ns}}$ & $1,1301^{\mathrm{ns}}$ & $-0,0148^{\mathrm{ns}}$ & $0,0356^{\mathrm{ns}}$ & $-0,3919^{\text {ns }}$ & $-0,1261^{\mathrm{ns}}$ \\
\hline 2 & $0,1516^{\mathrm{ns}}$ & $0,6884^{*}$ & $0,8075^{\text {ns }}$ & $0,1085^{* *}$ & $0,5512 * *$ & $-0,5009^{\mathrm{ns}}$ & $2,5025 * *$ \\
\hline 3 & $0,2102^{\mathrm{ns}}$ & $0,4939 *$ & $2,2587 * *$ & $0,0054^{\mathrm{ns}}$ & $0,4398 * *$ & $0,7935^{\text {ns }}$ & $1,8255^{* *}$ \\
\hline 4 & $0,0067^{\mathrm{ns}}$ & $1,1072 * *$ & $0,8343^{\text {ns }}$ & $0,0561 *$ & 0,2438 & $1,9688^{* *}$ & $3,8451 * *$ \\
\hline 5 & $0,0964^{\mathrm{ns}}$ & $0,1067^{\mathrm{ns}}$ & $0,6364^{\mathrm{ns}}$ & $-0,0027^{\mathrm{ns}}$ & $-0,1117$ & $-0,2906^{\mathrm{ns}}$ & $0,1263^{\mathrm{ns}}$ \\
\hline 6 & $0,0232 \mathrm{~ns}$ & $0,4955^{*}$ & $-0,4685^{\mathrm{ns}}$ & $-0,0188^{\mathrm{ns}}$ & 0,0538 & $-0,1078^{\mathrm{ns}}$ & $0,9126^{*}$ \\
\hline 7 & $0,6563 * *$ & $0,3772^{\text {ns }}$ & $1,4322 *$ & $-0,015^{\mathrm{ns}}$ & $-0,0913$ & $0,7449^{\mathrm{ns}}$ & $1,8627 * *$ \\
\hline 8 & $-0,0423^{\mathrm{ns}}$ & $-0,1013^{\mathrm{ns}}$ & $0,1838^{\mathrm{ns}}$ & $0,0422 *$ & $0,3305^{*}$ & $0,5748^{\mathrm{ns}}$ & $1,6267 * *$ \\
\hline 9 & $0,1675^{\mathrm{ns}}$ & $-0,0125^{\mathrm{ns}}$ & $1,4363^{*}$ & $0,0401 *$ & $0,1974^{\mathrm{ns}}$ & $0,5806^{\mathrm{ns}}$ & $0,8217 *$ \\
\hline 10 & $0,8817 * *$ & $-0,2309^{\mathrm{ns}}$ & $0,3463^{\text {ns }}$ & $0,0831 * *$ & $1,1715^{* *}$ & $-0,1471^{\mathrm{ns}}$ & $2,5159 * *$ \\
\hline 11 & $-0,1573^{\mathrm{ns}}$ & $0,1212^{\mathrm{ns}}$ & $0,0882^{\mathrm{ns}}$ & $0,103 * *$ & $1,4832 * *$ & $-0,5351^{\mathrm{ns}}$ & $4,2205 * *$ \\
\hline
\end{tabular}

**, ${ }^{*}$ Significativamente diferente de zero a $1 \%$ e $5 \%$ de probabilidade pelo teste $\mathrm{t}$, respectivamente.

COM, comprimento da fibra (UHM); UNIF, uniformidade do comprimento; RES, resistência da fibra; FIN, finura da fibra; IFC, índice de fibras curtas; PF, percentagem de fibra.

resposta à melhoria de ambiente, com destaque para 1 e 4, que apresentaram este comportamento para mais de uma característica. O índice de fibras curtas mostrou ser uma característica de alta previsibilidade. Quanto às linhagens, os genótipos 1 e 5 mostraram-se previsíveis para todas as características avaliadas.

\section{REFERÊNCIAS}

ALLARD, R.W.; BRADSHAW, A.D. Implications of genotype-environment interactions in applied plant breeding. Crop Science, v.4, n.5, p.503-504, 1964. Disponível em: $<$ https://www.crops.org/publications/cs/abstracts/4/5 CS0040050503 access $=0 \&$ view $=$ pd $>$. Acesso em: 22 set. 2014 . doi:10.2135/cropsci1964.0011183X000400050021x.

CARVALHO, L.P. Respostas correlacionadas do algodoeiro com a seleção para a coloração da fibra. Pesquisa Agropecuária Brasileira, v.38, n.1, p.79-83, 2003. Disponível em: $<\mathrm{http}: / / \mathrm{www}$. scielo.br/pdf/pab/v38n1/a11v38n1>. Acesso em: 22 set. 2014. doi:10.1590/S0100-204X2003000100011.

CARVALHO, L.P. et al. Adaptabilidade e estabilidade em cultivares de algodoeiro herbáceo. Pesquisa Agropecuária Brasileira, v.30, n.2 p.207-213, 1995. Disponível em: <file:///C:/Documents\%20 and\%20Settings/Windows\%20XP/Meus\%20documentos/ Downloads/4294-17616-1-PB.pdf >. Acesso em: 22 set. 2014.

CRUZ, C.D. Programa genes: biometria. Viçosa: UFV, 2006. $382 \mathrm{p}$.

CRUZ, C.D et al. Modelos biométricos aplicados ao melhoramento genético. Viçosa: UFV, 2004. 585p.

EBEHART, S.A.; RUSSELL, W.A. Stability parameters for comparing varieties. Crop Science, v.6, n.1, p.36-40, 1966. Disponível em: $\quad<\mathrm{http}: / /$ www.sap.uchile.cl/descargas/... fisiogenetica/Stability\%20parameters\%20for\%20comparing $\% 20$ varieties_Ebehart_Russell1966.pdf $>$. Acesso em: 22 set. 2014.
FARIAS, F.J.C. et al. Parâmetros de estabilidade propostos por Lin e Bins (1988) comparados com o método da regressão. Pesquisa Agropecuária Brasileira, v.32, n.3, p.407-414, 1997. Disponível em: $\quad<$ file://C:/Documents\%20and\%20Settings/Windows\%20 XP/Meus\%20documentos/Downloads/4657-56012-1-PB.pdf>. Acesso em: 22 set. 2014.

FEHR, W.R. Principles of cultivar development: Theory and technique. Ames: Iowa State University, 1987. 536p.

GOMES, F.P. Curso de estatística experimental. Piracicaba: Nobel, 1990. 468p.

SILVA FILHO, J.L. et al. Comparação de métodos para avaliar a adaptabilidade e estabilidade produtiva em algodoeiro. Pesquisa Agropecuária Brasileira, v.43, n.3, p.349-355, 2008. Disponível em: <http://www.scielo.br/pdf/pab/v43n3/a09v43n3.pdf>. Acesso em: 22 set. 2014. doi:10.1590/S0100-204X2008000300009.

MOREIRA, J. et al. Estabilidade de comportamento em cultivares de algodoeiro herbáceo em diversos ambientes. Campina Grande: Embrapa - CNPA, 1983. 58p. (Embrapa-CNPA. Boletim de Pesquisa, 13). Disponível em: $<\mathrm{http} / /$ www.sidalc.net/ cgi-bin/wxis.exe/?IsisScript=AGB.xis\&method $=$ post\&formato $=2$ \& cantidad $=1$ \&expresion $=\mathrm{mfn}=085027>$. Acesso em: 22 set. 2014.

MORELLO, C.L. et al. Adaptabilidade e estabilidade de linhagens finais de algodoeiro em Goiás. In: Congresso Brasileiro de Melhoramento de Plantas, 2005. Gramado, RS. Anais... Passo Fundo: Embrapa Trigo: SBMP, 2005. Disponível em: CD-Rom.

NG, E.H. et al. Stability Analysis of upland cotton in Texas. Crop Science, v.53, p.1-9, 2013. Disponível em: <https://www.crops. org/publications/cs/pdfs/53/4/1347>. Acesso em: 22 set. 2014. doi:10.2135/cropsci2012.10.059

PERCY, R.G.; KOHEL, R.J. Qualitative genetics. In: SMITH, C.W.; COTHREN, J.T. (Eds.). Cotton: origin, history, technology and production. New York: John Wiley, 1999. p.319-360.

SANTANA, J.C.F. et al. Parâmetros de estabilidade na comparação de cultivares de algodoeiro herbáceo. Pesquisa Agropecuária Brasileira,

Ciência Rural, v.45, n.4, abr, 2015. 
v.18, n.3, p.261-267, 1983. Disponível em: <http://seer.sct.embrapa.br/ index.php/pab/article/view/15202/9028>. Acesso em: 22 set. 2014.

SOBREIRA, E.S. et al. Estabilidade de cultivares de algodoeiro herbáceo nas condições do cerrado. In: Congresso Brasileiro de Melhoramento de Plantas, 2., 2003, Porto Seguro. Resumos... Porto Seguro: SBMP, 2003. p.35.

SOUZA, A.A. et al. Estabilidade e adaptabilidade do algodoeiro herbáceo no cerrado do Mato Grosso e Mato Grosso do Sul.
Pesquisa Agropecuária Brasileira, v.41, n.7, p.1125-1131, 2006. Disponível em: <http://seer.sct.embrapa.br/index.php/pab/article/ view/7255/4300>. Acesso em: 22 set. 2014. doi:10.1590/S0100$204 X 2006000700008$.

SUINAGA, F.A. et al. Phenotipic adaptability and stability of cotton cultivars in Mato Grosso State, Brazil. Pesquisa Agropecuária Tropical, v.36, n.3, p.145-150, 2006. Disponível em: <http://www.scielo.br/pdf/pab/v42n5/12.pdf>. Acesso em: 22 set. 2014. doi:10.1590/S0100-204X2007000500012.

Ciência Rural, v.45, n.4, abr, 2015. 